\title{
A Brief Survey on the Sociolinguistic Pattern of Khelma (Sakachep) in Relation to the Mediating Role of Multilingualism among the Native Speakers
}

\author{
Pushpa Renu Bhattacharyya a, * \\ ${ }^{a}$ Research Associate, Centre for Endangered Languages, Tezpur University, Napaam-784028, Tezpur, Assam, India \\ * Author Email: dr.pushparb@gmail.com \\ DOI: https://doi.org/10.34256/ijmrd2138 \\ Received: 26-07-2021; Revised: 28-08-2021; Accepted: 30-08-2021; Published: 01-09-2021
}

\begin{abstract}
Languages play a vital role in the formation of identity of a speech community with its unique features. The degree of usage of a language in various domains and the positive attitudes of the native speakers towards the language help to strengthen up and maintain the status, power and solidarity of the speech community. Very often the native speakers of the smaller known languages remain unaware of the risk of losing their language or about the process of language shifting. Today in the world of science and technology each and every speech community is practising multilingualism either directly or indirectly according to the demands of the basic needs in their daily lives. This paper is a result of an attempt to present a sociolinguistic survey on the language use, attitude and identity of native speakers of Khelma (Sakachep) in the district of Dima Hasao, Assam in North-East India towards their mother tongue as well as towards other languages spoken and used in different domains in the Khelma community according to their needs. The research work is carried out under CFEL, Tezpur University, Assam. Native speakers based on different age groups, gender, educational qualifications, occupational patterns, family types and as rural and urban dwellers were interviewed. The methods used for interview were personal interviews, group discussions, telephonic conversations and silent observations. The participants were asked a series of questions concerning their language, culture, traditions and also their feelings regarding other languages used in and around them.
\end{abstract}

Keywords: Khelma, Multilingualism, Sociolinguistics

Subject Specialization: Khelma (Sakachep) (Endangered Language)

\section{Introduction}

The Centre for Endangered Languages (CFEL), Tezpur University, Assam, India was established in the year 2014. The centre is carrying out research work and trying to motivate and create awareness among the native speakers of seven lesser known languages along with their cultures and traditions by promoting preservation, maintenance, revitalization, documentation and digitization of these speech communities. These seven lesser known languages belong to three states of North-East region viz, Biate, Hrangkhol and Khelma from Assam, Onaeme and Purum from Manipur and Yimchunger and Liangmai from Nagaland. The present paper is based on the sociolinguistics survey on the native speakers of Khelma (Sakachep) who represent ten Khelma villages which come under New Sangbar Community Development Block under Umrangso circle, Dima Hasao, Assam.

Khelma is an unclassified language which exhibits features of Kuki-Chin language group of the TibetoBurman language family. Khelma language as well as the community is known by an alternative name Sakachep. It must be mentioned that except in Dima Hasao district, the Khelmas are known as Sakachep in Cachar, Karbi Anglong, Hailaknadi and Karimganj districts of Assam and the neighbouring states like Mizoram, Meghalaya, Tripura and Nagaland. The language code according to Ethnologue is ISO 639-3 sch. The Khelmas are one of the smallest ethnic groups in the Kuki-Chin community in North-East India. It is believed that the term 'Sakachep' is 
derived from two words, namely: Sak and Chep. Sak means 'upper side' and Chep means 'using of chopstick' i.e., people residing in upland who use bamboo chopsticks to eat.

Khelma is the fifth-largest minority language group in the district of Dima-Hasao in terms of number of tribal language speakers following Dimasa, Karbi, Biate and Hrangkhol. It is believed that Khelmas have migrated from Tripura. According to the SIL Ethnologue (2003), the total population of this community is 5000 (approx.). According to UNESCO'S scales of language endangerment in terms of intergenerational transmission the status of the language is vulnerable Level 4. During the data collection, two varieties of the language viz. Hanle and Hante have been found, which are mutually intelligible. It is noticed that the total number of Hanle speakers is more than that of Hante speakers.

The entire Khelma population have converted to Christianity. Most of them depend entirely on agriculture for their livelihood. The cropping pattern of paddy among Khelmas is practiced in two cultivation types. The major form of farming practice commonly used by Khelmas is (i) Jhum Cultivation and the minor form of farming practice used by few is (ii) Wet Rice Cultivation (WRC) / Low (valley) Lands Rice cultivation.

\subsection{Methodology of the Survey}

The present study was conducted in ten Khelma villages viz, Baigaon, Bangphri(Ch ), Bangphri(H ), Dorbinsip, Kekrangsip, Tuisnanthuon, Tuizonte, Langlut(H), Langlut(Ch) and New Kekrangsip that come under New Sangbar Community Development Block under Umrangso circle, Dima Hasao, Assam. The participants (50 male and 50 female) selected for the study are native speakers of Khelma the age grouping of 15-80. The participants were classified into different age-groups viz. 15-25, 26-36, 37-47, 48-58, 59-69 and 70-80. In the age group15-25 there were 20 participants, in the age group 26-36 there were 20 participants, in the age group 37-47 there were 15 participants, in the age group 48-58 there were 20 participants, in the age group 59-69 there were 15 participants, in the age group 70-80 there were 10 participants. Both literate and illiterate participants were chosen for the interview. Among the total number of 100 participants, 80 were literate (male: 50 and female: 30) and 20 were illiterate, i.e., cannot read and write but can count (male: 5 and female: 15). Most of the participants were school dropouts and those with maximum qualifications were undergraduates. Most of the people reside in urban areas than rural areas and are multilingual.

After a brief introduction about the purpose of the study and instruction to the questionnaire, each selected participant was given the questionnaire, which they had to answer instantly. The participants took about 30 minutes or so to complete the task. In the present survey, the interview and questionnaire methods were used. The questionnaire was designed with both open and closed questions to elicit information and explore the degree of language use, attitude, and identity of the native speakers or the participants in the survey towards their mother tongue and other languages used by them. The questionnaire aimed to provide an opportunity for the participants to express their views in their own words as their choices were not fixed. The questionnaire was designed to know the preference in choice of languages, argumentation, interactional and conversational behaviour, etc. and to check the correlation in choice of patterns between the responses and attitudes of the participants. Group discussions and silent observations were also conducted. The interaction between the participants and the researcher covered more details than the responses received from the direct question of the questionnaire. The collected data were tabulated and statistically analysed for achieving the objectives. The paper reflects the native speakers' views towards their mother tongues and other languages spoken and used in different domains according to their needs.

\section{The Questionnaire}

The questionnaire was designed to find out: (i) what languages are preferred in different domains and the percentage of these languages used by the speakers (ii) to identify various factors contributing towards multilingualism and participant's attitude towards their mother tongue as well as other languages (iii) to find out the participants' level of self-declared fluency in their mother tongue. The questionnaire covered the following parts: 


\subsection{Various Domains of Language Use}

In Figure 1, we have some domains where Khelma, English, Hindi, Halflong Hindi and Biate are used. Khelma is the native language, Hindi and English are official languages of the state, Halflong Hindi is a variety of Hindi spoken in the Halflong area and is more of a lingua-franca, while Biate is a Kuki-Chin language spoken in the Dima-Hasao district. The Bible is translated in Biate hence we see the importance of this language amongst the locals.

\begin{tabular}{|l|l|}
\hline Domain & Language in Use \\
\hline Home & Khelma \\
\hline Office/workplace & English and Hindi \\
\hline Market place & English and Hindi \\
\hline Offering prayer & Haflong Hindi \\
\hline Community meetings & Biate and Mizo \\
\hline Socio-cultural gatherings & Khelma \\
\hline Friends & Khelma, Biate and Haflong Hindi \\
\hline Strangers & Haflong Hindi \\
\hline
\end{tabular}

Figure 1 shows the domains and languages used

\subsubsection{Observations}

The analysis of the questionnaire showed that:

- There are several receptive bilingual speakers in the Khelma community, who only speak Khelma, but they understand Haflong Hindi, a pidgin, enough to communicate. Most of the Khelma speakers use Khelma and Haflong Hindi for intercommunity communication. English is the official language as well as the medium of instruction; so the literates can communicate in English. From this observation, we can say that the Khelma community of the Dima-Hasao district is multilingual. During the survey, only three women were found to be monolingual in two of the villages viz. Kekrangsip and Dorbin.

- The participants prefer to use their mother tongue in the home domain and their comfort zones.

- The church is an interesting domain in the Khelma area, where the Bible reading is done and hymns are sung in Biate. The Bible in Khelma is in process yet to be published. So, the Biate Bible is used in the church. Generally, the language used to deliver sermons depends on the pastor. If he is a Biate speaker, then Biate is used for sermons. Pastors from outside Dima Hasao prefer to give a sermon in Mizo. Most of the Khelma people understand Mizo.

- In socio-cultural gatherings, a number of languages are used as people from different speech communities attend these functions. Khelma, Biate and Halflong Hindi find more use than others.

- The survey reveals that the participants assumed that Haflong Hindi is a variety of the standard Hindi taught in their schools. However the Halflong Hindi differs a lot from Standard Hindi.

- The Sakachep Literature Committee was set up in 1985. The members of the Sakachep Literature Committee consider themselves as fluent speakers of Khelma. The committee has not decided on which variety of Khelma to be used for formal writing. As both the Hanle and Hante varieties are used in intracommunication; we have a mix of both the varieties in their writings. Since its inception, the Sakachep Literature Committee has faced two challenges:

(a) To design the orthography and develop the writing system to meet the needs of the speakers of both language varieties and serve the community's purpose. 
(b) To decide which speech variety will be standardised to reflect the speech community or to find out a multilectal or multidialectal approach where the writing system does not represent one specific variety only, but through careful choices, it is designed to extend to both varieties.

The aim of the Sakachep Literature Committee is to arrive at a system of writing which would encompass both Hante and Hanle variety. During the initial stages of the translation of the Sakachep New Testament, the committee opted for Hante and then Hanle varieties. Finally, they translated the New Testament by mixing lexical items from both varieties. The people trained to translate the Testament were from both Hante and Hanle varieties. The Sakachep Literature Committee published the Testament by mixing lexical items from both varieties. In figures $2 a$ and Figure $2 b$ we have two excerpts taken from The Sakachep New Testament.

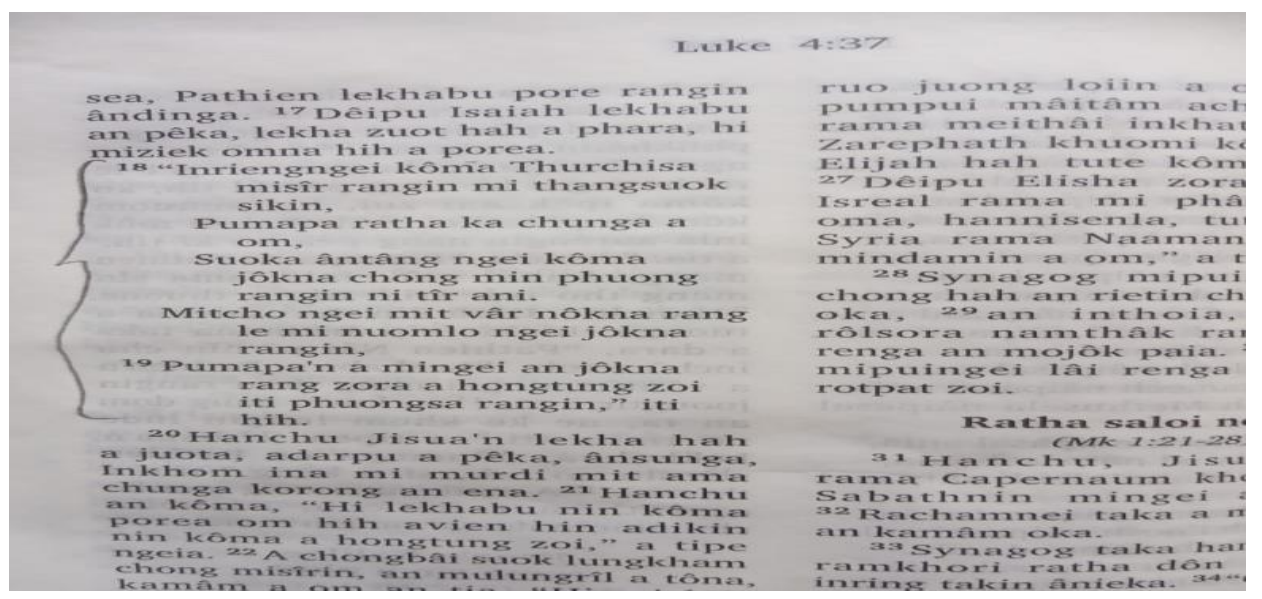

Figure 2a the mixing up a pattern of Hanle and Hante varieties in the Khelma writing system

In Figures $2 \mathrm{a}$ and $2 \mathrm{~b}$, we see the use of capital letters, abbreviations and the use of the apostrophe (') in the examples Pumapa'i (pumapa:i), pa'n (pain), can be considered a new pattern of writing for the indigenous speakers. The incorporation of punctuation marks in their literature is an impact of education. Most Khelma speakers opt for English medium schools. For a primarily oral community with no orthography of its own, the impact of modern education is evident in their translation.

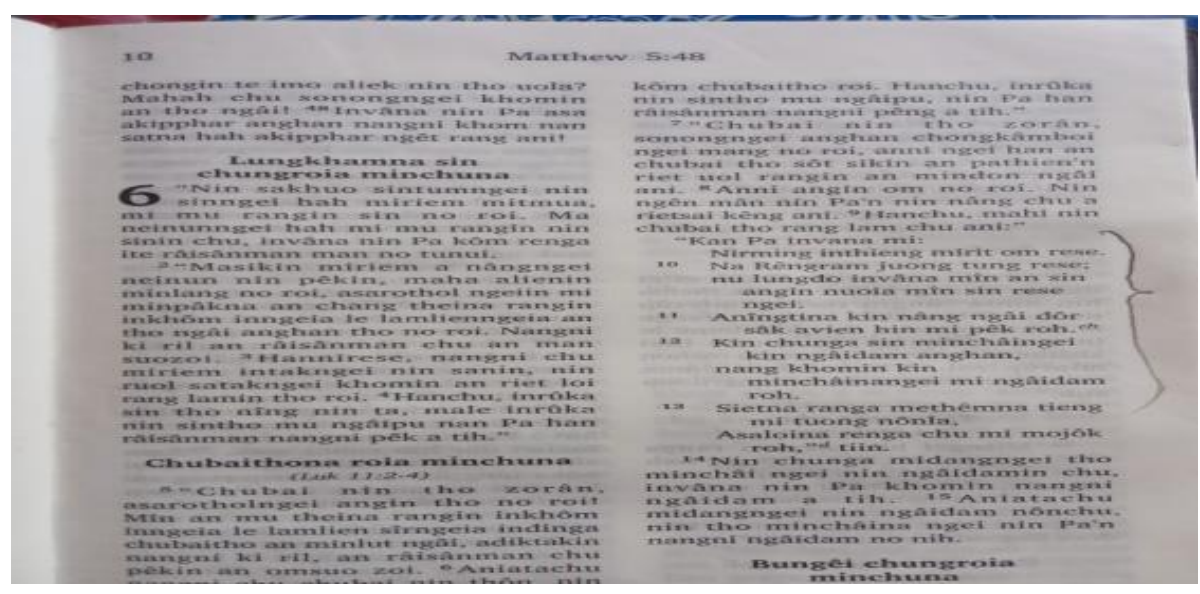

Figure $\mathbf{2} \mathbf{b}$ The mixing up pattern of Hanle and Hante varieties in the Khelma writing system

It must be mentioned that the third option of mixing in words from both the Hante and Hanle variety has been adopted by the Sakachep Literature Committee. Individuals belonging to either of the two varieties usually avoid the mixing of lexical items in a sentence. In one of the written tasks given to the respondents, it was observed that the Hante and Hanle speakers wrote in their variety. The response of the respondents was spontaneous. Given a choice they would prefer to write in their own variety. But in the process of formalizing the Khelma writing system, we see a conscious effort on the part of the Sakachep Literature Committee to incorporate lexical items from both varieties while framing a sentence. In most other domains like delivering public speeches or 
making announcements, the speakers use the variety they speak. The community has yet to adopt the written form developed by the committee.

\subsubsection{Preferences of languages}

Preferences of language in various domains found in the survey are shown in Figure 3 below.

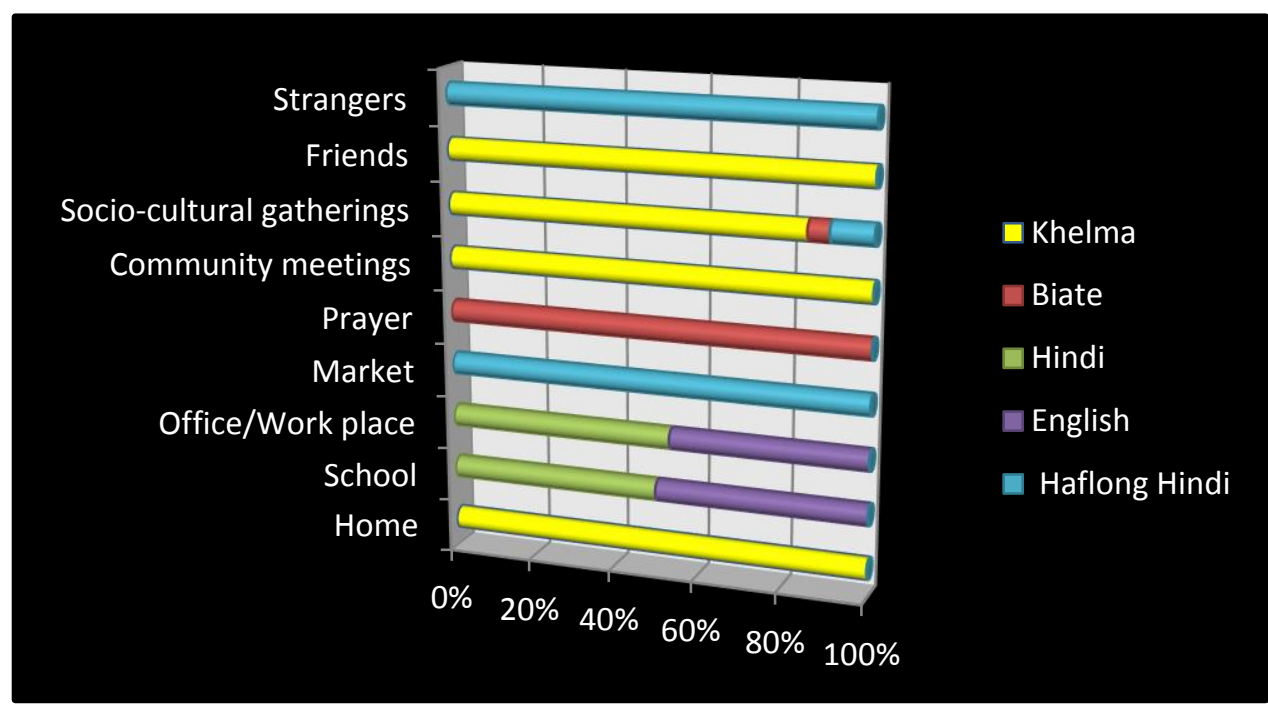

Figure 3 Preference of languages in various domains

\subsection{Khelma in Mass Media and Modern Technology}

The informants provided information that the use of Khelma in the mass media is limited:

\section{Radio:}

Two years ago, Khelma songs were broadcasted by All India Radio Station in Haflong twice a week for ten minutes in the morning and evening, but it is not done now. The native speakers informed they want to listen to few songs and at least the news in Khelma daily on the radio.

\section{Television: Nil}

Newspapers: Nil

Journals/Magazines/Books: The Sakachep New Testament

\section{Texting messages and mailing e-mails:}

Khelma speakers use to text messages in Khelma and Haflong Hindi using Roman script, very few can email in English.

Conversation over the phone: Khelma, Haflong Hindi and English

Public announcement: Khelma, Haflong Hindi

\section{Internet:}

Google provides very brief information about Sakachep or Khelma. There are few Sakachep blogs, but there are a few number of songs sung in Sakachep on Youtube.

\subsection{Language Used in Other Collective Activities of the Speech Community}

The Khelma community organizes a number of activities in which most of the community members take part. In Table1, we have a list of a number of indigenous activities performed collectively. While performing these collective activities, the community communicates with one another in Khelma. 
Table 1 Collective Activities in Khelma language

\section{Collective Activities}

Agriculture

Hunting

Fishing

Honey collecting

Elephant herding

Cleaning up rural streets

Collecting fire woods

Fetching water
Language Used

Khelma

Khelma

Khelma

Khelma

Khelma

Khelma

Khelma

Khelma

\subsection{Language Used in Various Verbal and Non-Verbal Domains}

When it comes to expressing feelings, emotions, greetings and performing certain physical and cognitive activities, the community prefer to use the native language. In Table2, we have a range of verbal and non-verbal domains where the mother tongue Khelma is used in most cases and Hindi, Halflong Hindi and Karbi are used in certain verbal domains like flattering, annoyance, singing, dancing, discourse with neighbours, as shown below.

Table 2 Languages used in verbal and non-verbal domains

\section{Verbal Domain}

Monologues

Counting

Complimenting

Measuring

Swearing

Abusing

Story telling

Joking

Asking riddles

Telling proverbs

Singing lullaby

Expressing fear

Expressing surprise

Flattering

Annoyances

Apologizing

Singing and dancing

Time telling

Discourse with neighbour

Arguing

Order/commands

\section{Non-Verbal}

Domain

Thinking

Dreaming

Khelma

Khelma

Khelma

Khelma

Khelma

Khelma

Khelma

Khelma

Khelma

Khelma

Khelma, Karbi

Khelma

Khelma

Khelma, Hindi

Khelma, Hindi

Khelma

Khelma, Biate, Hindi

Khelma

Khelma, Haflong Hindi

Khelma

Khelma

\section{Language Attitude}

Following questions were prepared to test the speakers' opinions and attitudes regarding the preservation of their mother tongue and to focus on and determine the factors responsible for the speakers' attitude towards their mother tongues. The responses to the questions are as follows: 
- Is your language easy to learn?

$100 \%$ of the participants answered positively that Khelma is easy to learn.

- Can you express your thoughts in your mother tongue?

Based on the result of self-assessment, each and every participant feels that he/she can express their thoughts in mother tongue.

- Do you accept the process of mixing words from other languages while speaking in your mother tongue?

$100 \%$ of the participants answered positively that they accept the process of mixing words from other languages while speaking in their mother tongue.

- Would you like to learn your mother tongue if there are facilities or will you teach your children to speak the language? If yes, why?

$100 \%$ of the participants answered, 'Yes, it is necessary to learn for our identity as a Khelma.'

- Do you think it is better suited for performing various socio-economic and cultural needs?

$100 \%$ of the participants answered negatively that Khelma is not better suited for performing diverse socio-economic and cultural needs.

- Do you think other languages are easy to learn? If yes, why?

$100 \%$ of the participants answered negatively that other languages are not easy but complicated to learn.

- Do you think one language is enough for all usages?

$100 \%$ of the participants answered negatively that one language is not enough for all usages.

- Do you think learning other languages will improve your knowledge?

$100 \%$ of the participants answered positively that learning other languages would improve their knowledge.

- Can you and your children speak the language fluently?

$100 \%$ of the participants answered negatively that they and their children could not speak Khelma fluently.

- Do you prefer to marry a person who cannot speak your mother tongue?

$100 \%$ of the participants answered positively that they prefer to marry a person who cannot speak Khelma.

- What is your feeling about your language after twenty years from now?

$100 \%$ of the participants answered that it would not remain as correct or original as today.

- Whether the writing system of mixed up of two varieties is a desired one?

Hante speakers said Hante is easy and Hanle speakers said Hanle is easy to learn, speak and write. They also admitted they never tried the mixed variety. When they were asked to read out the writings written on that pattern, they said they could read and understood. But when they were asked to translate a story from English to Khelma by using any of these writing patterns, all the informants chose their own language variety. They also admitted that they were trying to write such lengthy prose (i.e., the story) for the first time because they write in Khelma only to text messages on their mobile phones.

Following are the questions asked to the members of the Sakachep Literature Committee -

- Do the members of the Khelma community agree on a variety that could serve as a standard or do they wish for the writing system to accommodate both varieties? 
All the ten members of the Sakachep Literature Committee answered that there is no community conflict between the speakers of these two language varieties. There is no demeaning attitude of speakers towards each other. As most of the committee members are speakers of the Hante variety and they are educated, having a strong financial background compared to the speakers of Hanle variety, at the beginning, the translators and writers tended to elevate Hante variety above Hanle. They also admitted that they consider Hante variety as a prestigious variety as it is rhythmic (vowel harmony is noticed). But later on, the committee has decided to give the freedom of choice to write on any of these three patterns, i.e., Hanle only, Hante only and the mixed up of Hanle and Hante with which the writer is comfortable to write. No member of the community had raised any question on the Khelma writing system to date. Hanle is the original variety spoken in the Dima Hasao district and the Hante variety is mainly spoken in Nagaland. All these members who are Hante speakers had migrated from Nagaland between 1985-2005.

\section{- What are the steps taken by the Sakachep Literature Committee to teach the speakers about orthography and the writing system?}

According to those members, due to lack of financial support, the members of the committee are unable to organize mass literacy campaigns or maximum community involvement programme to promote good practices like to train or teach the speakers about orthography and the writing system in a formal way. But if someone comes to them to seek knowledge or help, they provide help and suggestions.

\subsection{Findings and Observations}

- Due to many economic and logistical problems, the speakers of lesser known languages tend to view on the language attitude based on their individual experiences of life. They want to learn Khelma as they call and introduce themselves as Khelma people. The Khelma speakers seemed not so confident about the fluency in their mother tongue. Most of the speakers made statements like We do not know correct Khelma. The language we use is not so correct. Original Khelma is spoken by the old speakers only. Most of the Khelma speakers replied positively that they would teach Khelma to their children. For socioeconomic reasons, they want to learn other languages like Hindi and English because it would be profitable to provide jobs. All the speakers agreed that knowing English and Hindi was beneficial for getting jobs and other opportunities. Although the native speakers have answered that they use Khelma in domains like counting and measuring, in reality, it is noticed that they hardly use their traditional system of measuring in their daily lives. Terms like first, second for counting and litre, kilogram, mile, meter, etc., for measuring in use are very frequently noticed in their regular speech habits.

- The role of a speech community in preserving lesser known language and culture through developing an orthography and writing system helps prevent the lesser known languages from endangerment. Unfortunately, the orthography and writing system of Khelmas do not reflect the community's attitude, but a group of native speaker's attitude towards the proposed system is due to lack of awareness. As a result, neither any excitement is noticed nor loyalty seen in the process. As most of the Khelma speech community members are illiterate, awareness for the preservation of language and culture is rising very slowly. Acceptability of the orthography and the writing system is very much tied to the identity of a speech community. So, when the third pattern of the Khelma writing system, i.e., mixing up of two language varieties in a single sentence, is introduced to the Khelmas another option was also given to choose among the three patterns to preserve their language and culture. A large number of speakers do not know what is going on with their language. The decision of the committee has always become the ultimate decision of the speech community.

\section{Language Identity}

Following are the questions prepared to test the speakers' opinions regarding the language identity. The common answers represent how the native speakers considered themselves as members of the Khelma community in terms of their cultural and linguistic identity.

- The language variety of which village is most famous and why?

Indian J Multiling Res Dev., 2(3) (2021), 65-75 | 72 
The villagers of Kekrangsip speak the original form of the language. Because the villagers converted to Christianity only in the year 2005. They are still practicing our cultural traditions partially.

- Which of the language variety of your language is considered as the most pleasant or prestigious?

$100 \%$ of the respondents Hante because it is rhythmic (Vowel harmony is observed).

- Do the people of neighbouring languages learn your language? If yes, why?

$100 \%$ of the respondents answered negatively that the people of neighbouring communities are not learning their language.

- Do you feel the language is going to shift?

$100 \%$ of the respondents answered negatively that he/she does not feel that the language is going to shift.

- How do you react when the native speaker of your language use other language while speaking to the speaker of his/her mother tongue?

$100 \%$ of the participants answered positively that it sounds good.

- Which language variety is totally acceptable?

Although, $100 \%$ of the participants opine that Hante is considered as the most pleasant because it is rhythmic, but for writing books or translation purposes they considered both Hanle and Hante.

\section{Summary and Some Observations}

From the above analysis it is evident that the Khelma speech community is practising multilingualism depending on their demographic, socio-economic and cultural requirements and they have a mixed attitude regarding their mother tongue. The aptitude, competence and proficiency of the native speakers in different languages vary. There is a deep urge of choosing their mother tongue as the first preferred at home domain. The feelings of insecurity in language competency is noticed when the most of the young speakers admitted that they are not speaking the original form of the language. The old generation did not speak about the originality. They simply admitted that what they knew they spoke. The very few number of native speakers of Khelma both young and adult feels the need of preserving their language, culture and traditions and also understand the implications of the mother tongue in their daily lives. The young adult speakers opine that by learning English and Hindi they can earn and maintain prestige in the society, because, one can acquire anything if he or she is economically strong. So, for them acquiring a job is the primary or basic need while maintaining their language and culture is secondary although, they consider it as necessary. Community loyalty is appreciated by all the native speakers, but the practice of the process of teaching and learning of the mother tongue is not being done by the native speakers practically neither in a formal or informal way. The survivability of Khelma is questionable in the near future. The opinions of males and females of both rural and urban areas were same about their mother tongue and other languages. The implementation of trilingual language formula of the Government of India is also influencing in their choice of preferences in different contexts. The need of education and increased number of migration to urban areas results in keeping themselves away from their traditional and cultural roots.

The usage of multilingualism has both positive and negative impact on the daily lives of the Khelma people. The native speakers feel more relaxed in communicating in their own languages. The participants believe that the best way to convey their identity is in their mother tongue, because it carries their traditional cultural heritage but there is a strong sense of understanding that a language and a culture cannot survive without usage and practice. They are also in favour of promoting other languages as well as admitted that they use lots of borrowed words in their daily speech. Very few people have a sense of fear and insecurity for their own identity while some others believe that the development of the community is only possible through the process of teaching, learning and using the languages like Hindi and English that provides better life-style with other opportunities. All 
the participants agreed with the view that extended family pattern helps in following and preserving the language as well as the traditions and culture.

\section{Apart from the questionnaire few additional observations were made during the survey-}

- Sometimes the native speakers face difficulties to tell the truth. While the children who are studying in boarding schools used to come home during holidays, most of the parents like to speak with them in Hindi. But, during the face to face interview they told that they would like to talk in Khelma with their children because that is the only way for them to save and preserve their language, traditions and culture.

- There were several young speakers who had been married to speakers from other speech communities and these parents and their children communicate with each other in Hindi at home. It is also noticed that in some cases young parents speak to their children in Hindi even though parents were the native speaker of Khelma. This was mostly seen with families who lived outside the village i.e., in urban areas. When it was pointed out to these families that they were not speaking in their mother tongue, the parents replied that they spoke in Khelma too.

- Same cases are found with children's games that are played by singing a song or a rhyme. Those children studying in the urban areas prefer to use Hindi while playing such games and those children studying in the village schools or those who are not going to schools prefer to play in their mother tongue.

- Personal names play a powerful role in establishing, maintaining and conveying one's socio-cultural identity. In Khelma, the name of an individual is written preceding by name of great grandfather (paternal)/grandfather's (paternal) name following by great grandmother (paternal/maternal)/grand mother's name (paternal/maternal) and followed by given name of the individual and the surname. Through this systematic pattern one can trace genealogical line accurately for many generations. They believe that the dead or alive ancestors of the individual might stay near him or her and protect him or her from all evils. The Khelma names are written without any space in between. In writing style or orthography it seems like one word only although it is a combination of three names with three syllables, e.g., Lienthoisuan Saithuvai carries three separate syllables in both name and surname. The full name i.e., all the syllables are barred from uttering by a person of the same community, because it is considered as an offence in the society and a feeling of insult to its owner. During the survey it is noticed that $5 \%$ of the participants are using the abbreviated forms (e.g., N.J. Lal Khelma) instead of full names of their grandparents and $10 \%$ of the participants are using individual's name (e.g., Bul Nistaral) only in the written form instead of the traditional three syllabic names.

- Though the Khelmas have hardly enjoyed the facilities of electricity and internet, yet the role of modern equipment of modern world like mass media and communication technology have influenced them. The young parents prefer to name the new born baby with new names (e.g., Arkaina, Yuna) after the character found in video games.

- The young parents prefer to name their children with Christian or western names (e.g., David, Gracy), Hindu names (e.g., Ajay, Pretty) and names borrowed from other ethnic community like Biate, Mizo (e.g., Boi, Lomi).

- The young and new generations are using and accepting some new trends and patterns in the naming system, while few grandparents and elderly people dislike these. Because most of them faced difficulties in uttering these names, they do not have any emotional feelings or attachment with those names compared to the names that belong to their own culture. Such differences in opinion eventually led some parents and relatives to practice of giving children two names- the traditional one along with a Christian or western name (e.g.,Jonathan lianneingir Neibom, Elizabeth Lalneikip Vaichal), the traditional name of the individual is used as a pet name. In contrast, the Christian or western name is used for formal purposes. As a result these individuals received nick/pet names which was not found earlier in their traditional culture. 


\section{Conclusion}

The survey reveals that multilingualism is not only effecting in the listening, speaking, reading, writing and counting or measuring skills of the native speakers of Khelma by expanding their knowledges in various fields, but emotionally also they are crossing the traditional cultural boundary.

\section{Supplementary Information}

Demographic description of ten Khelma villages and Questionnaire and Interview Format for the Survey on the Sociolinguistic Pattern of Khelma (Sakachep).

\section{References}

Sakachep at Ethnologue $\left(18^{\text {th }}\right.$ ed,, 2015$)$

\section{Acknowledgement}

My sincere gratitude to Prof. Madhumita Barbora, Coordinator CFEL, Tezpur University, Assam. I would like to express my special thanks of gratitude to all participants without whom the present study could not have been completed.

\section{Funding}

No funding was received for conducting this study.

\section{Does this article screened for similarity?}

Yes

\section{Conflict of interest}

The Author has no conflicts of interest to declare that they are relevant to the content of this article.

\section{About the License}

(C) The author 2021. The text of this article is open access and licensed under a Creative Commons Attribution 4.0 International License

\section{Cite this Article}

Pushpa Renu Bhattacharyya, A Brief Survey on the Sociolinguistic Pattern of Khelma (Sakachep) in Relation to the Mediating Role of Multilingualism among the Native Speakers, Indian Journal of Multilingual Research and Development, Vol 2, Iss 3, (2021) 65-75. DOl: https://doi.org/10.34256/ijmrd2138 